\title{
PENERAPAN SOCIOTECHNICAL SYSTEM PADA DATA COLLECTION SYSTEM
}

\author{
Dian Felita Tanoto; Yonathan Marcellinus; Monica Hidajat \\ School of Computer Science, Bina Nusantara University, \\ Jl. Kebon Jeruk Raya 27, Kebon Jeruk \\ Jakarta Barat 11530, Indonesia \\ dtanoto@binus.edu, ymarcellinus@binus.edu,mhidajat@binus.edu
}

\begin{abstract}
Humans and technology are two things that can not be separated. The rate of population growth, which is growing rapidly, proportional to the needs of people in many ways. Each activity and human needs, should be documented, so any activity and human needs can be predicted. Therefore, the data need to be collected and stored properly, effectively, and accuratel. Socio-Technical System is expected to assist and facilitate human in performing the collection and storage of data. Socio-Technical System can be applied by taking into account various aspects ranging from social, psychological, computer science, and technical. Methods of SocioTechnical implementation consists of requirements analysis, system design, implementation, testing, deployment, maintenance. In the testing phase, it should be noted the social and psychological aspects of the user.
\end{abstract}

Keywords: sociotechnical system, collection system

\begin{abstract}
ABSTRAK
Manusia dan teknologi adalah dua hal yang tidak dapat dipisahkan. Tingkat pertumbuhan penduduk yang berkembang pesat berbanding lurus dengan kebutuhan manusia dalam banyak hal. Setiap aktivitas dan kebutuhan manusia harus didokumentasikan sehingga setiap aktivitas dan kebutuhan manusia bisa diprediksi. Oleh karena itu, data perlu dikumpulkan dan disimpan sebaik-baiknya, efektif, dan akurat. Socio-Technical System diharapkan dapat membantu dan mempermudah manusia dalam melakukan pengumpulan dan penyimpanan data.. Socio-Technical System dapat diterapkan dengan memperhatikan berbagai aspek mulai dari sosial, psikologis, computer science, dan teknikal. Metode penerapan dari Socio-Technical terdiri dari analisis kebutuhan, perancangan sistem, implementasi, testing, deployment, maintenance. Pada tahap testing, perlu diperhatikan juga aspek sosial dan psikologi dari pengguna.
\end{abstract}

Kata kunci: sociotechnical system, collection system 


\section{PENDAHULUAN}

Perkembangan jaman saat ini sangat menuntut kita untuk menggunakan teknologi dalam berbagai bidang, baik untuk kebutuhan pribadi maupun kebutuhan peorangan (perusahaan). Teknologi tersebut digunakan untuk berbagai macam kebutuhan, salah satunya untuk koleksi data-data yang dibutuhkan untuk dokumentasi ataupun analisa untuk perkembangan dan tujuan tertentu.Dengan adanya Socio - Technical System membantu kita untuk mengerjakan pekerjaan-pekerjaan yang mungkin di luar batas kemampuan manusia.

\section{METODE}

Metodologi yang akan digunakan untuk penulisan makalah ini adalah sebagai berikut: (1) Tinjauan Pustaka; mengumpulkan data yang berasal dari buku atau literatur tertulis lainnya sebagai landasan teori penulisan. (2) Metode Deskriptif; dilakukan dengan studi kasus, studi komparatif, menganalisis tingkah laku maupun dokumenter yang ada untuk mencari unsur, ciri, sifat suatu kejadian.

Berikut ini merupakan metodologi yang dapat digunakan untuk menerapkan socio-technical system:

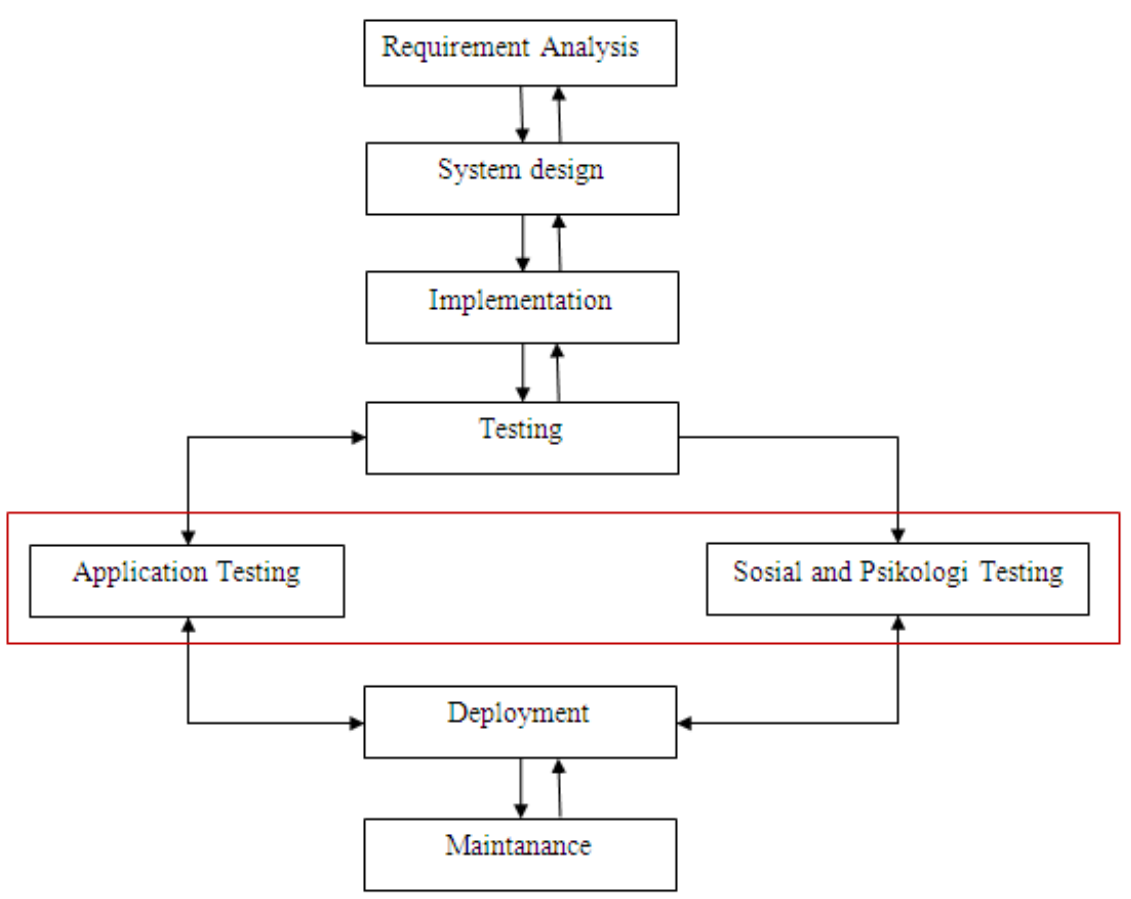

Gambar 1 Metodologi Sociotechnical System

Pada tahapan testing dilakukan pula uji dari segi sosial dan psikologi dari pengguna dengan memberikan questioner atau surver terhadap pengguna setelah tahapan uji aplikasi selesai dilaksanakan. Kemudian dilakukan perhitungan data mengenai kondisi psikologis dari pengguna saat menggunakan aplikasi yang ada. 


\section{HASIL DAN PEMBAHASAN}

\section{Sociotechnical System}

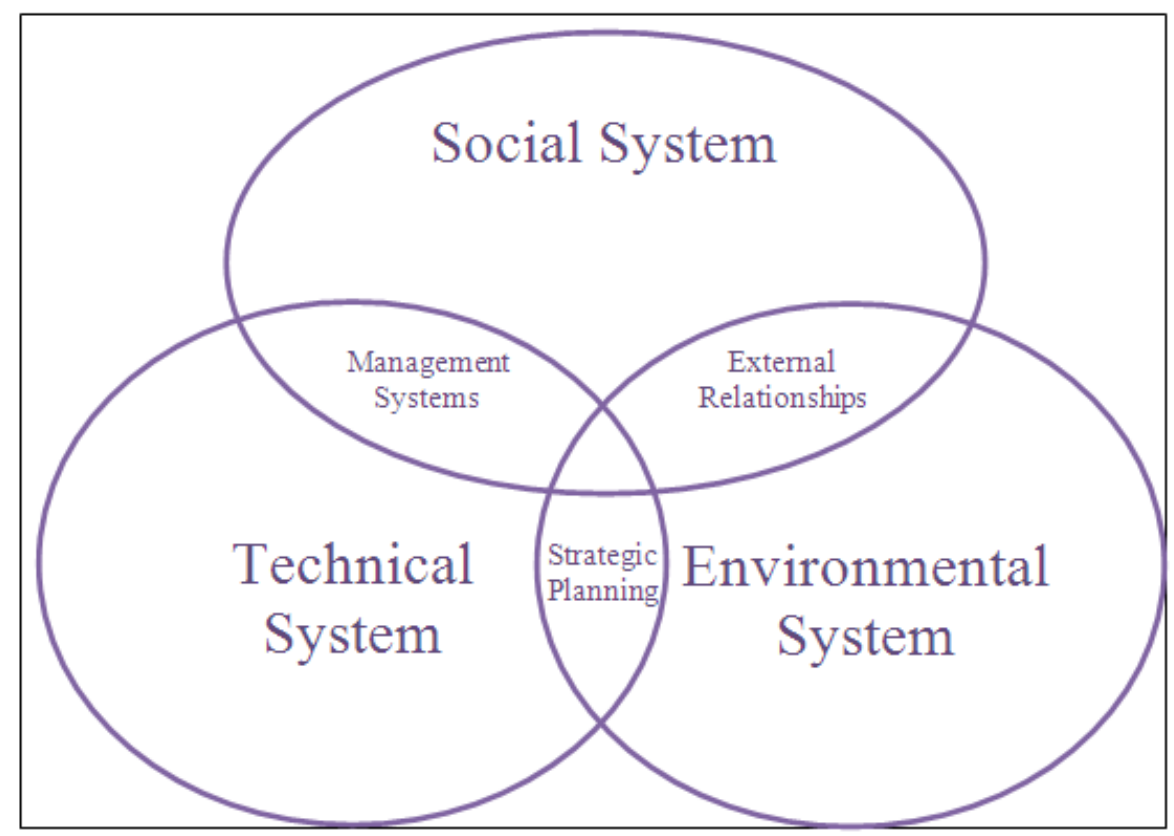

Gambar 2 Socio-Technical System

Socio - Technical System adalah sistem interaksi antara manusia dan teknologi, di mana kegiatan manusia dipermudah dengan menggunakan teknologi tersebut. Faktor-faktor yang membuat Socio-Technical System mempermudah kegiatan manusia antara lain: (1) Hardware yang terdiri dari perangkat penghubung jaringan (kabel, router, hub, dll) sampai pada perangkat komputer pengguna. (2) Software merupakan bagian internal Socio - Technical dimana terjadi interaksi antara manusia dan komputer untuk menggerakan sebuah system. Software sendiri menjadi penghubung interaksi para pengguna dan hardware yang digunakan. Namun penggunaan sebuah software dalam beberapa SocioTechnical yang berbeda dapat menyebabkan masalah yang disebabkan ketidak cocokan. Untuk itu sebaiknya setiap sistem Socio - Technical menggunakan software yang diciptakan khusus atau memang didesain hanya untuk sistem tersebut sehingga kesalahan bisa dikurangi. (3) Physical surroundings atau bangunan fisik juga berpengaruh dalam menentukan aturan-aturan dalam SocioTechnical yang diciptakan. (4) People di mana sistem juga dirancang menyesuaikan dengan penggunanya. People di sini bukanlah hanya orang perseorangan, namun juga untuk tiap role, maupun kelompok yang berperan dalam penerapan system ini. (5) Procedures dimana langkah-langkah pekerjaan dari sistem itu sendiri. Prosedur sangat berpengaruh dalam merancang software yang dirancang untuk system tersebut. (5) Laws dan regulations sedikit mirip dengan procedures, namun hukum dan peraturan lebih menekankan pada tindakan yang terjadi diluar prosedure yang seharusnya (6) Data dan data structures dimana data yang harus diketahui dalam sebuah sistem tertentu, apakah data-data tersebut yang harus disimpan menggunakan format tertentu akan mempengaruhi design sistem Socio-Technical 
Menurut Sommerville (2010) faktor-faktor di atas dibedakan dalam beberapa layer sebagai berikut:

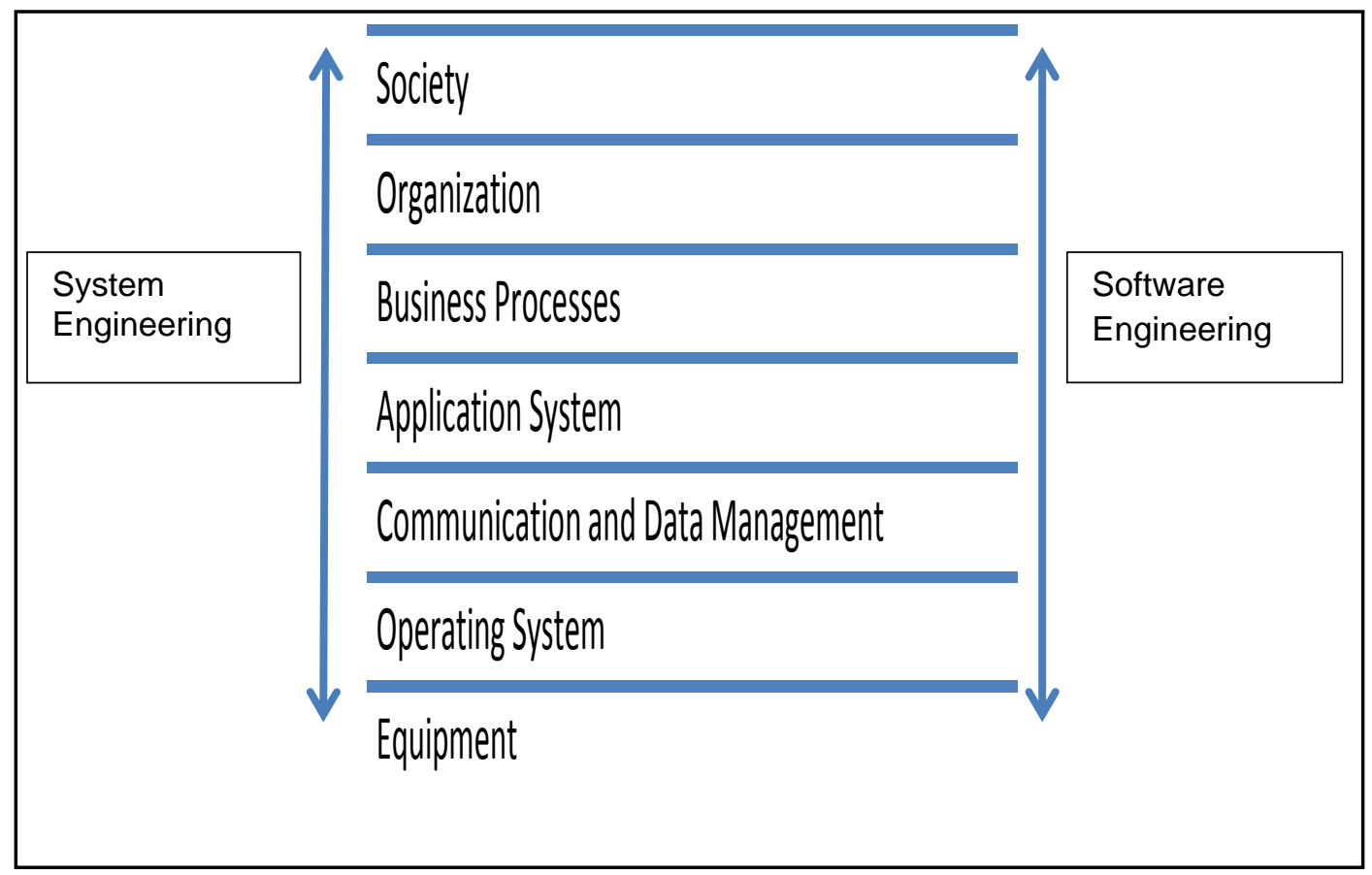

Gambar 3 The Socio-Technical System stack

Socio-Technical terdiri dari dua aspek yaitu aspek sosial dan aspek technical. Dimana pekerjaan manusia dapat dibantu dengan adanya teknologi yang semakin berkembang. Namun seiring berkembang teknologi, terkadang sistem yang diciptakan justru sulit untuk dipelajari oleh pengguna. Kendala ini dapat disebabkan oleh kompleksitas design yang diciptakan, sistem yang sulit dipelajari oleh pengguna atau tampilan user interface yang langka sehingga menyebabkan kesalahan pengertian misalnya dengan penggunaan icon-icon yang tak umum sehingga menyebabkan human error saat diterapkan.

Contohnya adalah pada kecelakan pesawat Garuda Indonesia pada tanggal 23 November 2001 yang dikutip dalam artikel yang ditulis oleh Aliandrina (2012). Dimana kecelakan yang terjadi disebabkan penerapan Socio-Technical di mana sistem baru yang diciptakan terlalu kompleks. Menurut Sommerville (2010) ada beberapa dua faktor terbesar yang menyebabkan kegagalan sistem, antara lain: (a) Software yang stack pada saat pengoperasian. (b) Pengguna tidak dapat menangani kesalahan yang terjadi karena tidak mengerti penggunaan sistem

Faktor-faktor yang harus diperhatikan dalam perancangan sistem Socio - Technical, antara lain: (a) Kehandalan hardware. (b) Kehandalan software. (c) Kehandalan pengguna. Sistem ini dinyatakan berhasil jika dapat meningkatkan kualitas layanan perusahaan dan menambah pendapatan. Sistem yang dirancang juga harus didesain untuk menghindari kesalahan yang terjadi yang disebabkan oleh human error. Contohnya, penggunaan icon-icon yang sering digunakan pada sistem yang diharapkan dapat menanggulangi kesalahan yang terjadi, misalnya, dengan button back untuk kembali ke modul sebelumnya atau dengan memberi pesan kepastian apakah benar akan melakukan proses tertentu yang biasanya dilakukan ketika menekan button yang melakukan proses proses penting. 
Perubahan sistem biasanya membutuhkan biaya yang tinggi dikarenakan beberapa alasan, antara lain: (a) Usulan perubahan yang harus dianalisis dengan sangat berhati-hati dan perubahan yang terjadi harus berkontribusi pada system. (b) Subsistem yang harus diubah apakah bergantung pada subsistem lainnya dan apakah perubahan akan berpengaruh negatif pada sistem lainnya. (c) Perubahan yang dilakukan harus didokumentasikan dan dipastikan mengapa harus terjadi perubahan. (d) Berpeluang terjadi kerusakan sistem yang disebabkan perubahan sistem sehingga membutuhkan biaya tambahan

Faktor-faktor yang mempengaruhi permintaan perubahan design dan operasi sistem Socio Technical adalah perubahan proses bisnis, perubahan pekerjaan dan perubahan organisasi. Menurut penelitian yang dilakukan oleh Wihlborg dan Soderholm (2013) perubahan pada Socio-Technical System merupakan proses yang rumit dan berkelanjutan. Berikut beberapa prinsip yang diterapkan untuk Socio-Technical, antara lain: (a) Sistem kerja yang terdiri dari serangkaian kegiatan yang membentuk keseluruhan fungsi, menjadi unit dasar. (b) Lebih berpusat pada pekerjaan kelompok bukan individual. (c) Peraturan internal adalah peraturan kelompok, peraturan individu ditambahkan sebagai peraturan tambahan yang diatur oleh supervisor. (d) Pembagian berdasar pada perbedaan fungsi bukan perbedaan unit kerja. (e) Dan lebih mementingkan pembagian per bagian bukan per peran kerja. (f) Memperlakukan individu sebagai pelengkap mesin bukan perpanjangan dari itu. (g) Lebih baik meningkatkan variasi untuk individu dan organisasi, dibandingkan mengurangi variasi untuk birokrasi.

Socio-Technical yang perlu dilakukan pada tingkatan yang luas dari mikro ke makro yang saling terkait: (a) Primary work system; sistem yang dapat digunakan untuk serangkaian kegiatan yang ada di subsistem diidentifikasi dan dibatasi dari organisasi seperti departemen atau layanan unit. Primary work system ini bisa terdiri dari kelompok kecil maupun besar. (b) Whole organization system; mementingkan lembaga yang berdiri sendiri dan lembaga publik. (c) Macrosocial system; termasuk system public, sector industry dan lembaga yang beroperasi di berbagai tingkat masyarakat

Dasar teori Socio-Technical membagi beberapa computing level berdasarkan discipline perspektif komputer dalam hubungan antara mesin dan manusia, berikut penjelasannya akan digambarkan dalam table berikut.

Tabel 1 Computing levels as discipline perspectives

\begin{tabular}{lll}
\hline Level & Examples & Discipline \\
\hline Community & $\begin{array}{l}\text { Norma, budaya, hukum, zeitgeist, } \\
\text { sangsi, peraturan }\end{array}$ & Sociology \\
Personal & $\begin{array}{l}\text { Semantik, sikap, kepercayaan, } \\
\text { perasaan, ide-ide }\end{array}$ & Psychology \\
Informational & $\begin{array}{l}\text { Program, data, bandwidth, memori } \\
\text { Mechanical }\end{array}$ & Computer science \\
& $\begin{array}{l}\text { Hardware, motherboard, telephone, } \\
\text { fax }\end{array}$ & Engineering \\
\hline
\end{tabular}

Dimana technology yang dimaksud adalah device/hardware yang diciptakan, sedangkan Information Technology adalah yang membuat technology dapat berfungsi yaitu dengan adanya software yang membantu manusia untuk menerjemahkan bahasa manusia ke bahasa komputer dan sebaliknya. Sedangkan HCI (Human Computer Interaction) adalah hubungan antara IT dan pengguna IT tersebut. STS (Socio - Technical System) adalah hubungan antara HCI dengan community, dengan kata lain, system yang digunakan oleh sekelompok orang. Berikut gambaran-gambarang mengenai Socio - Technical System: 


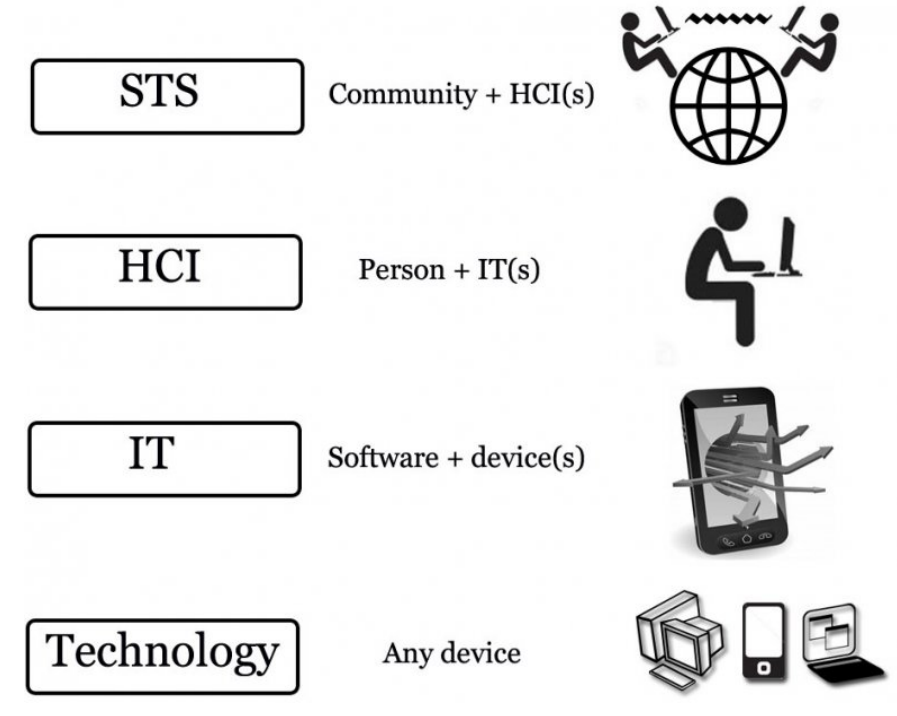

Gambar 4 Socio - Technical System

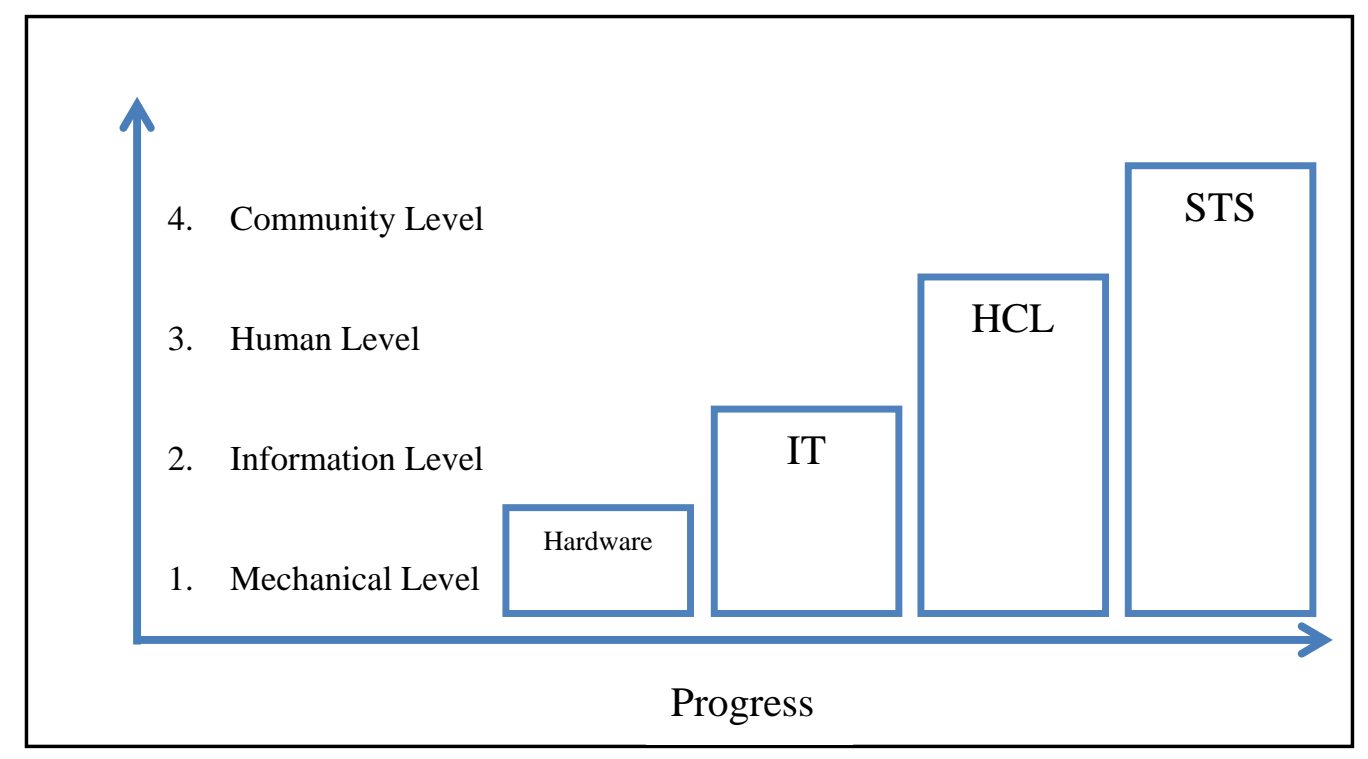

Gambar 5 Socio - Technical System vision

\section{Data Collection System}

Data Collection System adalah sistem pengaturan penyimpanan data dalam perusahaan. Dimana setiap perusahaan pasti mempunyai format penamaan file tersendiri yang memudahkan dalam proses pencarian data. Selama ini proses ini masih dilakukan dengan cara manual. Dimana setiap karyawan menyimpan data dengan formatnya masing masing. Namun, karena banyak pergantian karyawan baru dan karyawan lama, format penyimpanan data menjadi tidak konsisten karena terdapat perbedaan format antara pegawai baru dan lama. Oleh sebab itu, terjadi kesulitan dalam pencarian data-data lama yang pernah disimpan oleh pegawai yang telah mengundurkan diri. 
Dalam penerapan Data Collection System, perusahaan GHG Institute memiliki manajemen yang baik, karena bagian terpenting dari program manajemen GHG adalah sebuah desain yang efisien untuk membangun sistem dan konsistensi replikasi inventori dari tahun ke tahun. Desain adalah bagian terpenting ketika mempertimbangkan pergantian sumber daya manusia, dari SDM lama ke SDM baru yang berpeluang menghilangkan konsistensi format penyimpanan data. Dalam kasus ini, organisasi kecil selalu memiliki keterbatasan waktu dan sumber daya untuk melakukan hal tersebut. United Nations Foundation (UNF) mengatasi kendala tersebut dengan mempersatukan pengumpulan data dan sistem manajemen untuk mendukung proses pembangunan inventori.

Selain itu terdapat beberapa masalah yang diteliti seperti pendataan persalinan di Inggris yang dilakukan oleh Kenney dan Macfarlane (1999) tentang sejauh mana data bersalin yang dikumpulkan dan bagaimana data tersebut dicatat. Untuk mengidentifikasi masalah yang dapat mempengaruhi ketersediaan data tersebut di seluruh NHS, tercatat 167 (81\%) kuesioner yang kembali dengan 166 kuesioner yang valid dari seluruh kuesioner yang diberikan. Dari data yang valid tersebut sekitar 17 dari 19 data berasal dari HES (Hospital Episode Statistic) persalinan. Dari 158 Data yang dikumpulkan, sekitar 40 dari 45 data dipilih dari Korner dataset. Hanya 18 data yang dikumpulkan dari kelima item yang diberikan berasal dari indikator sukses, dan 17 data tidak. Dari 58 data yang valid, ternyata data disimpan pada kertas terlebih dahulu.

Sistem komputerisasi informasi sistem persalinan telah digunakan oleh 106 orang (63\%) dari data yang valid, tetapi masih banyak data yang dicatat pada kertas terlebih dahulu dan 34 data tidak diaudit. Dari data keseluruhan yang valid tercatat masih banyak data yang dianalisa tetapi tidak dikumpulkan secara rutin ditingkat nasional, terdapat18 data juga tidak dianalisa oleh HES dan 17 data tidak dianalisa oleh Korner data. Kesimpulannya adalah perbaikan masih diperlukan dalam kualitas, kelengkapan dan ketersediaan data bersalin di tingkat nasional, terutama jika strategi informasi NHS ingin berhasil dilaksanakan. Meskipun sebagian besar item data dalam dataset nasional dicatat secara lokal, tapi masih kurang variasi dalam cara pendefinisian, perekaman dan penganalisisan data, serta kurang hubungan antara sistem komputer dalam membatasi akses, ketersediaan, dan penggunaan data di tingkat lokal, kabupaten, dan tingkat nasional.

\section{Penerapan Sociotechnical System pada Data Collection System}

Penerapan Socio-Technical System pada Data Collection System dapat dilakukan dengan menciptakan sebuah aplikasi untuk mempermudah sistem Data Collection. Format penyimpanan data akan konsisten sehingga mempermudah proses formating, foldering dan pencarian data. Namun dalam penerapan sistemn arus didesain dengan user interface yang mudah dipahami oleh pengguna untuk menghindari kesalahan yang disebabkan oleh human error. Dalam hal ini pengguna biasanya adalah karyawan perusahaan yang ingin menerapkan aplikasi ini pada sistem data collectionnya. Untuk tindakan pengamanan agar user memahami penggunaan aplikasi ini, dapat juga diadakan briefing untuk cara penggunaan aplikasi kepada para pengguna aplikasi.

Prosedur, data, data structure, laws dan regulation yang diterapkan di perusahaan sangat mempengaruhi desain aplikasi yang akan dibuat. Contohnya pada penerimaan mahasiswa baru. Maka langkah-langkah apa saja yang harus dilakukan oleh seorang calon mahasiswa baru. Misalnya dengan mengisi sebuah formulir pendaftaran. Data calon mahasiswa apa saja yang diperlukan universitas. Misalnya data nama, sekolah asal dan nilai rata-rata ujian akhirnya. Data yang telah diinput akan divalidasi kebenarannya dengan peraturan yang diterapkan oleh universitas misalkan nama tidak boleh mengandung huruf. Kemudian data akan disimpan dengan format tertentu yang telah disiapkan perusahaan agar menjaga konsistensinya, contoh: Folmulir Pendaftaran_<nama pendaftaran mahasiswa>.xlsx. Jika nilai dari rata - rata ujian akhir calon mahasiswa tersebut kurang dari standar yang ditetapkan universitas, maka akan ditandai dalam formating file datanya. Maka applikasi untuk Socio-Technical ini akan dirancang dengan adanya modul pendaftaran mahasiswa yang isinya meminta input berupa nama, sekolah asal, dan rata - rata nilai ujian akhir dari calon mahasiswa. Dan ketika data-data tersebut tidak diinput sesuai dengan format yang diinginkan contohnya nama calon 
mahasiswa diinput menggunakan angka, maka modul tersebut akan menampilkan pesan kesalahan. Kemudian data yang telah diinput applikasi akan melakukan penyimpanan dengan format penamaan yang diinginkan.

\section{SIMPULAN}

Kesimpulan dari penerapan Socio - Technical System pada Data Collection System adalah sistem ini akan sangat membantu dalam mempermudah dalam proses inputing, formatting, penyimpanan dan pencarian data. Penerapan sistem socio - technical dapat dilakukan dengan melakukan metodologi terdiri dari analisis kebutuhan, perancangan sistem, implementasi, testing, deployment, maintenance. Pada tahapan pengujian, akan dilakukan pula uji survei terhadap kondisi psikologis dan sosial. Jika hasil survei menunjukkan bahwa sistem tidak sesuai dengan kondisi sosial yang ada, maka akan dilakukan perbaikan dari sistem yang ada.

Dari case study di atas penerapannya terhadap faktor-faktor yang mempengaruhi Technical System antara lain: (1) Hardware merupakan semua perangkat computer dan perangkat jaringan penghubung computer di gedung universitas tersebut. (2) Software merupakan aplikasi yang akan dirancang untuk mempermudah proses saving, formatting, and searching data. (3) Physical surroundings adalah bangunan fisik dari universitas tersebut. (4) People adalah karyawan, stakeholder maupun semua orang yang berperan dalam pengoprasikan system. (5) Procedures adalah langkahlangkah yang dibutuhkan dalam sistem misalnya modul pendaftaran mahasiswa. (6) Laws dan regulations adalah aturan yang menjaga agar procedures berjalan lancar, dalam hal ini menjaga agar data yang diinput benar contohnya validasi nama tidak boleh angka. (7) Data dan data structures adalah jenis data yang harus diinput dan formatnya misalnya dikasus ini adalah pada modul pendaftaran mahasiswa dibutuhkan data nama mahasiswa, alamat sekolah terakhir dan nilai rata-rata ujiannya dimana data-data tersebut harus disimpan dalam format "FolmulirPendaftaran_<nama pendaftaran mahasiswa>.xlsx" Namun perlu banyak faktor yang diperhatikan dalam penerapan sistem tersebut seperti yang telah dijelaskan di atas. Jika dalam penerapan sistem terjadi kesalahan dapat menyebabkan kesulitan yang lebih besar. Perubahan sistem yang dilakukan juga membutuhkan biaya yang tinggi dan waktu yang lama. Sehingga prancangan dan penerapannya harus dilakukan dengan perancangan yang matang.

\section{DAFTAR PUSTAKA}

Aliandrina, D. (2012). Keselamatan Penerbangan dari Perspektif Complex Socio-Technical System. Diaskses pada August 30, 2013 dari http://www.ilmuterbang.com/artikel-mainmenu29/keselamatan-penerbangan-mainmenu-48/655-keselamatan-penerbangan-dari-perspektifcomplex-socio-technical-system-.

Kenney, N., Macfarlane, A. (1999). Identifying problems with data collection at a local level: Survey of NHS maternity units in England. British Medical Journal, International edition, 319, 61922.

Sommerville, I. (2010). Software Engineering Ninth Edition. Addison. Wesley Publishing.

Wihlborg, E., Soderholm, K. (2013). Mediators in action: Organizing sociotechnical system change. Technology in Society, 35, 267-275. 